\title{
Specificity of Biomarker Detection in Microfluidic Sensors
}

\author{
Praneet Prakash ${ }^{1, a}$, Manoj Varma ${ }^{1,2,{ }^{*}}$ \\ ${ }^{1}$ Centre for Nanoscience and Engineering, Indian Institute of Science, Bangalore 560012, India \\ ${ }^{2}$ Robert Bosch Centre of Cyber-Physical Systems, Indian Institute of Science, Bangalore 560012, India \\ a) Present address: Warwick Integrative Synthetic Biology Centre, University of Warwick, Coventry, \\ CV4 7AL, United Kingdom.
}

Author to whom correspondence to be addressed: "mvarma@iisc.ac.in

\section{ABSTRACT}

The microfluidics based point-of-care (POC) sensing devices offer unmatched possibilities of fast and high throughput diagnosis over conventional strategies. A major challenge for the early detection of disease is the significantly lower concentration of biomarkers as compared to the interfering noise molecules. In this work, we investigate the 'reaction parameter' phase space to identify suitable reaction parameters to enhance biomarker detection specificity. Under similar target biomarker and noise concentration levels, we show that a target biomarker is more likely to be detected at low concentrations and weak target and noisereceptor binding kinetics. Importantly, a simulation verified time-scale based methodology is developed to guide the appropriate choice of biomarkers for specific detection. This study demonstrates the prospect of successful POC diagnostic devices during early stage of diseases such as cancer.

\section{INTRODUCTION}

The incubation period for the development of pathophysiological conditions varies from a few days in malaria to several years for diseases such as cancer and AIDS ${ }^{1}$. The late diagnosis of lethal and invasive diseases such as cancer leads to higher mortality rate. Thus, early detection of disease is crucial step towards reduction of mortality rate due to the disease progression. The detection of biomarker molecules in the presence of noise molecules is a key requirement for early diagnosis ${ }^{2}$. Over the years, several sensing approaches relying on electrochemical, optical and mechanical phenomena have been pursued with considerable success $^{3-5}$. However, many of them can't be extended to point of care (POC) sensing systems due to their higher cost and system complexity ${ }^{6}$. The prominent biomarker detection techniques currently in use are gel electrophoresis, mass spectrometry and antigen-antibody 
assays $^{7-9}$. These are laboratory intensive techniques requiring highly qualified technicians to perform and analyse the test results. The immunoassay based antigen-antibody test such as ELISA are promising but employs multiple steps making it complex to implement in POC tests $^{10}$.

The single step antigen-antibody tests are most promising as they rely on specific reactions and are simple enough to be implemented in POC setups. The viability of such tests relies heavily on high concentration and uniqueness of the biomarker. For instance, blood sugar test during diabetes is based on electrochemistry and reliably works in the presence of high sugar content $(\sim 1 \mathrm{mM})^{11,12}$. Similarly, pregnancy tests are definitive due to highly specific binding reaction of monoclonal antibody and $\beta$-subunit of $\mathrm{hCG}^{13}$ which is significantly elevated postpregnancy. The antigen-antibody binding approach remain unsuitable for early stage diagnosis of diseases such as cancer, where biomarkers are present in ultra-low concentrations $(\sim \mathrm{pM})^{14,15}$. In such scenario, microfluidics based biosensors are most appealing as the analyte solution can be continuously pumped until the sensor captures appropriate number of biomarker molecules required for reliable detection ${ }^{9,16}$. The usual microfluidic biosensor set-up involves the immobilization of receptors (antibody) on a solid surface that captures target molecules (antigen) from analyte solution based on their affinity ${ }^{17,18}$. The analyte molecules to be detected bind on the sensor surface resulting in the change of a physical variable leading to its detection. Researchers have already demonstrated ultra-sensitive biosensors with detection limit of fM-aM concentrations, however, they fail to achieve required level of specificity in the presence of non-specific noise molecules ${ }^{19,20}$. Thus, the diagnostic breakthrough depends on distinguishing target analyte molecules from a mixture of other very similar molecules.

In this work, we study the competition between target and noise receptor binding kinetics and their implication towards specific detection of target molecules. The microfluidic based biosensor device is modelled in commercial FEM environment 'COMSOL'21 to study the reaction parameter phase space.

\section{THEORY AND MODELLING}

\section{Numerical Simulation of Surface Biosensors}

The presence of target molecules in ultra-low concentrations during early stages of a disease is a major impediment towards reliable diagnosis. To overcome this limitation, biosensors are 
often housed in a microfluidic chamber (Fig. 1), where, a continuous flow of analyte solution maintains a steady analyte molecule concentration over the sensor surface. The target biomarkers react with the receptors coated over sensor surface to form target-receptor complex which is detected by various readout methods such as change in refractive index or electrical conductance.

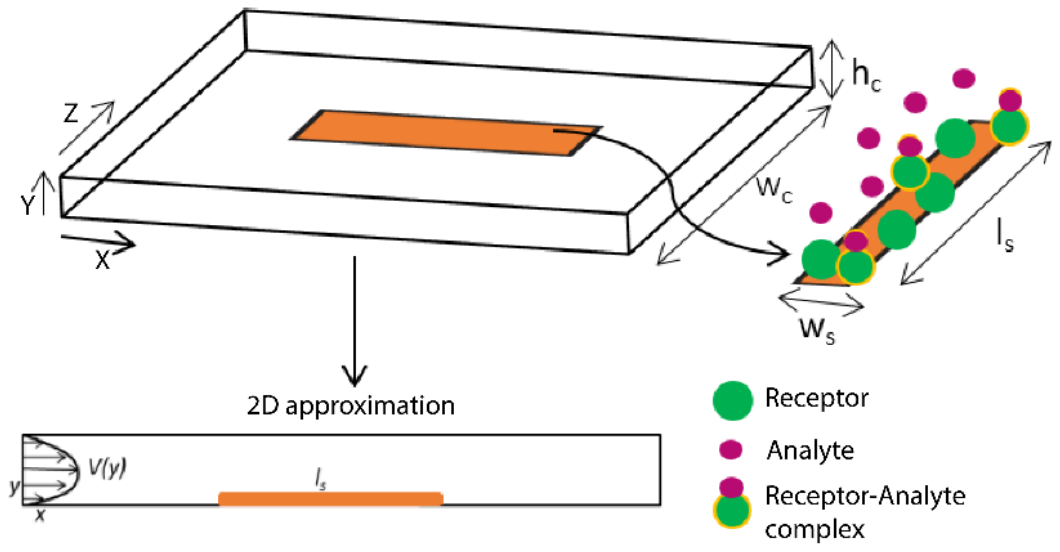

FIG. 1. A scheme showing microfluidic based surface biosensors (length of sensor, $l_{s}=100 \mu \mathrm{m}$ ). The analyte solution containing target molecules is flushed over receptor coated sensor surface, where, they bind to form analyte-receptor complex.

The flow profile of analyte solution is given by Navier-Stokes equation (Eq. 1), whereas, Convection-Diffusion equation (Eq. 2) is employed to trace the concentration variation within the microfluidic channel.

$$
\begin{gathered}
\rho\left(\frac{\delta \mathrm{v}}{\delta \mathrm{t}}+\mathrm{v} \cdot \nabla \mathrm{v}\right)=-\nabla \mathrm{p}+\mu \nabla^{2} \mathrm{v},(\mathrm{x}, \mathrm{y}) \\
\frac{\delta \mathrm{c}}{\delta \mathrm{t}}=\nabla \cdot(\mathrm{D} \nabla \mathrm{c})-\nabla \cdot(\mathrm{vc}),(\mathrm{x}, \mathrm{y})
\end{gathered}
$$

where, $\mathrm{v}$ is the convective velocity of analyte, $\mathrm{c}$ is the analyte concentration, and $\mathrm{D}$ is the diffusion coefficient. In the presence of single analyte molecules, the analyte-receptor binding kinetics can be expressed as:

$$
\frac{\partial \mathrm{b}(\mathrm{t})}{\partial \mathrm{t}}=\mathrm{K}_{\mathrm{on}} \mathrm{c}_{(\mathrm{y}=0)}\left(\mathrm{b}_{\mathrm{m}}-\mathrm{b}(\mathrm{t})\right)-\mathrm{K}_{\mathrm{off}} \mathrm{b}(\mathrm{t})
$$

where, $b$ is the analyte-receptor complex concentration, $b_{m}$ is the maximum number of receptor sites, $\left(b_{m}-b\right)$ are the free receptor sites, $K_{o n}$ and $K_{o f f}$ are forward and backward reaction rate respectively. The bound analyte-receptor complex at equilibrium $\left(b_{e q}\right)$ depends only on the reaction rate and can be expressed as: 


$$
\frac{b_{\text {eq }}}{b_{m}}=\frac{C_{o} K_{o n} / K_{\text {off }}}{1+C_{o} K_{o n} / K_{\text {off }}}
$$

The equilibrium time is however system dependent and relies on reaction as well as transport parameters. We numerically calculate the evolution of analyte-receptor complex over time by using Eq. 1 - 3 along with no-slip boundary condition as shown in Fig. 2.

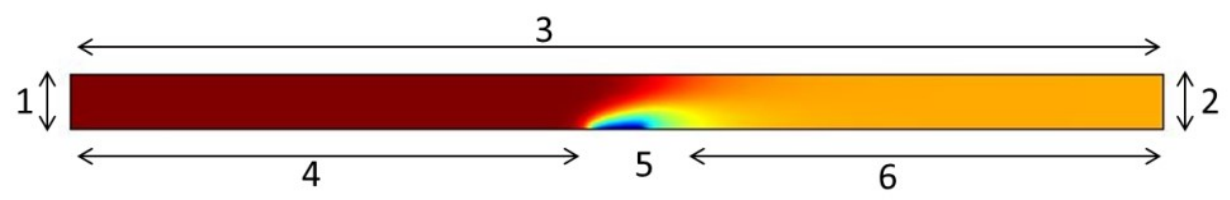

FIG. 2. Boundary 1 - inlet, Boundary 2 - outlet, Boundary 3, 4, 6 - no flux condition, Boundary 5 negative flux of analyte molecules over surface sensor due to analyte-receptor reaction kinetics.

\section{Analytical Prediction of Equilibrium Time}

The analyte molecules diffuse perpendicular to the direction of convective flow to bind with receptors sites. The ratio of the diffusive vs. convective transport is defined as Peclet number 22,23 :

$$
\mathrm{P}_{\mathrm{e}}=\frac{\mathrm{Q}}{\mathrm{DW}_{\mathrm{c}}}=\frac{\text { diffusive time }}{\text { convective time }}
$$

where, $\mathrm{Q}$ is the flow rate of analyte solution, $\mathrm{D}$ is the diffusion coefficient of analytes and $\mathrm{W}_{\mathrm{c}}$ is the width of microfluidic channel ${ }^{24}$. A constant flux of analyte molecules over sensor surface can only be maintained at a high Peclet number $\left(P_{e} \gg 1\right)$ which enables the analytical estimation of equilibrium time. At high Peclet number, a biosensor operates either in reaction or transport limited regime which is determined by relative dominance of reactive and diffusive flux. The ratio of reactive to diffusive flux is known as Damkohler number ${ }^{25}$ :

$$
\mathrm{D}_{\mathrm{a}}=\frac{\mathrm{K}_{\mathrm{on}} \mathrm{b}_{\mathrm{m}} \mathrm{l}_{\mathrm{s}}}{\mathrm{D} \mathcal{F}}=\frac{\text { reactive flux }}{\text { diffusive flux }}
$$

where, $\mathrm{K}_{\mathrm{on}}$ is forward rate of reaction between target and receptor molecules, $\mathrm{b}_{\mathrm{m}}$ is the density of receptor sites, $\mathrm{l}_{\mathrm{S}}$ is the sensor length, $\mathrm{D}$ is the diffusion of target molecules and $\mathcal{F} \approx(0.81) \sqrt[3]{\left(6 \mathrm{P}_{\mathrm{e}} \mathrm{l}_{\mathrm{s}}^{2} / \mathrm{h}_{\mathrm{c}}^{2}\right)}$ is the diffusive flux of target molecules over the sensor surface ${ }^{26}$.

A biosensor operates in reaction limited regime $\left(D_{a} \ll 1\right)$ if the flux of target molecules over sensor surface is much larger than target-receptor binding kinetics. Accordingly, equilibrium time (Eq. 7) can be predicted using reaction limited expressions:

$$
\tau_{\mathrm{eq}}=\left(\mathrm{K}_{\mathrm{off}}+\mathrm{K}_{\mathrm{on}} \mathrm{C}_{\mathrm{o}}\right)^{-1}
$$


Similarly, if reactions are limited by diffusive flux $\left(D_{a} \gg 1\right)$ then the equilibrium time can be expressed as ${ }^{16}$ :

$$
\mathrm{T}_{\mathrm{eq}}=\frac{\mathrm{K}_{\mathrm{on}} \mathrm{b}_{\mathrm{m}} \mathrm{l}_{\mathrm{s}}}{\mathrm{D} \mathcal{F}\left(\mathrm{K}_{\mathrm{off}}+\mathrm{K}_{\mathrm{on}} \mathrm{C}_{\mathrm{o}}\right)}=\mathrm{D}_{\mathrm{a}} \tau_{\mathrm{eq}}
$$

High Interference Reaction Regime $\left(\mathrm{K}_{\mathrm{on}} \mathrm{C}_{\mathbf{o}} / \mathrm{K}_{\mathrm{off}} \gg \mathbf{1}\right)$

We explored high interference reaction regime $\mathrm{K}_{\mathrm{on}} \mathrm{C}_{\mathrm{o}} / \mathrm{K}_{\mathrm{off}} \gg 1$ assuming Peclet number $\mathrm{P}_{\mathrm{e}}=10^{4}\left(\mathrm{Q}=300 \mu \mathrm{L} \mathrm{min}{ }^{-1}\right)$. The surface biosensor is modelled to be in the middle of microfluidic chamber having a length of $l_{s}=100 \mu \mathrm{m}$. The height of microfluidic channel $\mathrm{h}_{\mathrm{c}}=100 \mu \mathrm{m}$ whereas width of channel $\mathrm{W}_{\mathrm{c}}=500 \mu \mathrm{m}$. The number of receptor sites is optimized at $b_{m}=10^{15}$ site $m^{-216,27}$. Most of the biomarkers are protein molecules whose diffusion coefficient in water is of the order of $D=10^{-11} \mathrm{~m}^{2} \mathrm{~s}^{-128}$.

The analyte-receptor binding kinetic is studied in (Fig. 3a) by varying backward reaction rate $\left(\mathrm{K}_{\mathrm{off}}=10^{-5}-10^{-8} \mathrm{~s}^{-1}\right)$ at a fixed forward reaction rate $\left(\mathrm{K}_{\mathrm{on}}=10^{6} \mathrm{M}^{-1} \mathrm{~s}^{-1}\right)$ and initial concentration $\left(\mathrm{C}_{\mathrm{o}}=1 \mathrm{nM}\right)$ satisfying $\mathrm{K}_{\mathrm{on}} \mathrm{C}_{\mathrm{o}} \gg \mathrm{K}_{\mathrm{off}}$. The concentration curve of analytereceptor complex collapses even though $\mathrm{K}_{\mathrm{off}}$ is varied up to 4 orders. Further, over a timescale of $4000 \mathrm{sec}$, the receptor sites are completely occupied by the analyte-receptor complex. Since, $\mathrm{K}_{\mathrm{on}}=10^{6} \mathrm{M}^{-1} \mathrm{~s}^{-1}$ results in low $\mathrm{D}_{\mathrm{a}}=0.52$ the equilibrium concentration and time can be expressed by Eq. 4 and 7. Evidently, the concentration curves collapse (Fig. 3(a)) for a fixed $K_{o n}$ in the regime $K_{o n} C_{o} / K_{o f f} \gg 1$. Alternatively, analyte-receptor binding kinetics is studied by varying forward reaction rate $\mathrm{K}_{\mathrm{on}}=10^{5}-10^{8} \mathrm{M}^{-1} \mathrm{~s}^{-1}$ at a fixed $\mathrm{K}_{\mathrm{off}}=10^{-6} \mathrm{~s}^{-1}, \mathrm{C}_{\mathrm{o}}=1 \mathrm{nM}$ in Fig. 3(b). We see a shift in concentration curves at lower $\mathrm{K}_{\mathrm{on}}$ which progressively decreases at higher $\mathrm{K}_{\mathrm{on}}=10^{7}$ and $10^{8} \mathrm{M}^{-1} \mathrm{~s}^{-1}$ for which $\mathrm{D}_{\mathrm{a}}=$ 5.23 and 52.3 respectively. Hence, the sensor operates in transport limited regime, where equilibrium time can be expressed by Eq. 8. Interestingly, under the condition $\mathrm{K}_{\mathrm{on}} \mathrm{C}_{\mathrm{o}} \gg \mathrm{K}_{\mathrm{off}}$, Eq. 8 reduces to $\mathrm{T}_{\mathrm{eq}}=\mathrm{b}_{\mathrm{m}} \mathrm{l}_{\mathrm{s}} / \mathrm{DF} \mathrm{C}_{\mathrm{o}}$ predicting no dependence on reaction rates whatsoever.

Understandably, a significant interference from noise molecule is expected if both target and noise molecules are present in analyte solution and satisfy $\mathrm{K}_{\mathrm{on}} \mathrm{C}_{\mathrm{o}} \gg \mathrm{K}_{\mathrm{off}}$. Further, the targetreceptor and noise-receptor binding kinetics may remain indistinguishable with respect to $K_{\text {on }}$ in reaction limited regime $\left(D_{a} \ll 1\right)$ and with respect to both $K_{o n}$ and $K_{o f f}$ in transport limited regime $\left(D_{a} \gg 1\right)$. 

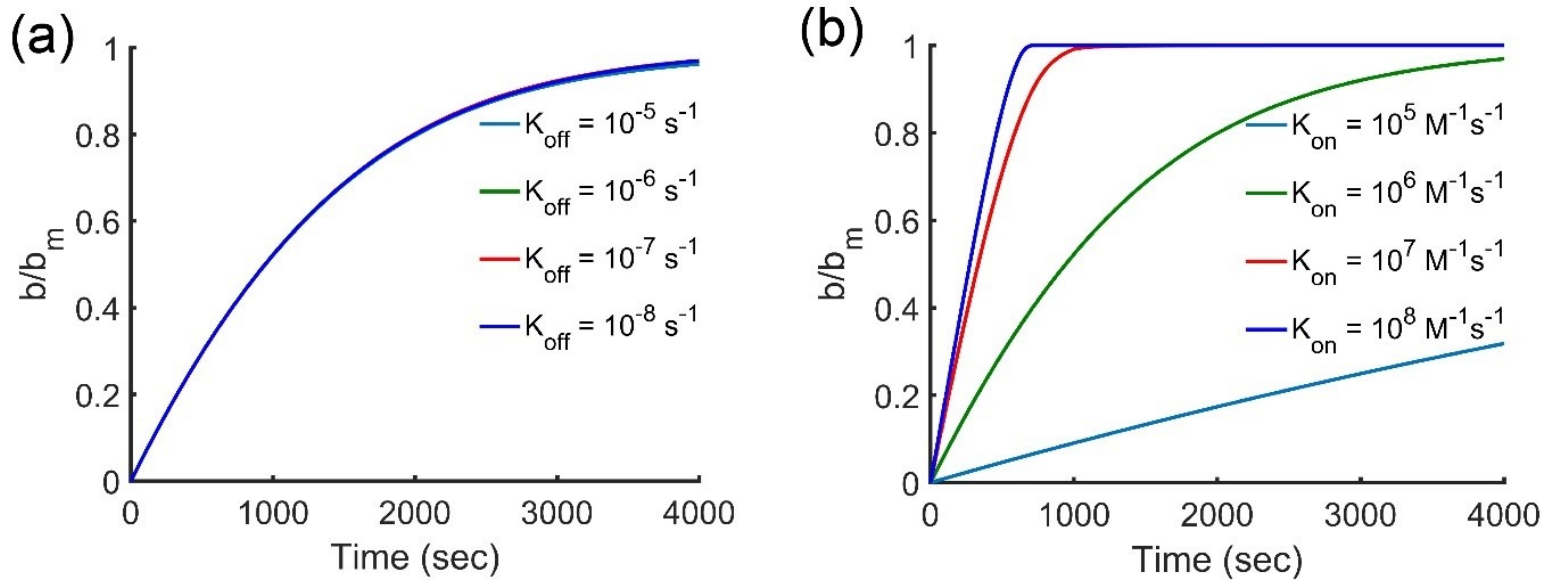

FIG. 3. The plot of analyte-receptor binding kinetics with time at various $K_{o f f}$ and $K_{o n}$. (a) The binding kinetics collapses for various backward reaction rate $\left(\mathrm{K}_{\text {off }}=10^{-5}, 10^{-6}, 10^{-7}\right.$ and $\left.10^{-8} \mathrm{~s}^{-1}\right)$ at fixed $\mathrm{C}_{\mathrm{o}}=1 \mathrm{nM}$ and $\mathrm{K}_{\mathrm{on}}=10^{6} \mathrm{M}^{-1} \mathrm{~s}^{-1}$. (b) The binding kinetics progressively decreases for higher forward reaction rates $\mathrm{K}_{\mathrm{on}}=10^{5}, 10^{6}, 10^{7}, 10^{8} \mathrm{M}^{-1} \mathrm{~s}^{-1}$ at fixed $\mathrm{C}_{\mathrm{o}}=1 \mathrm{nM}, \mathrm{K}_{\mathrm{off}}=10^{-6} \mathrm{~s}^{-1}$.

\section{RESULTS AND DISCUSSION}

We study the interference due to noise molecules in the target-receptor binding kinetics. The concentration of target biomarker and noise molecule is varied in the range $\mu \mathrm{M}-\mathrm{pM}$ from moderate to low concentrations. The reaction dissociation constant $\left(\mathrm{K}_{\mathrm{d}}=\mathrm{K}_{\mathrm{off}} / \mathrm{K}_{\mathrm{on}}\right)$ is varied from $1 \mathrm{M}-1 \mathrm{aM}$ accounting for weak to strong reactions. For the specificity analysis, we assumed an upper time limit of $\sim 1000 \mathrm{sec}$ as quick response time is desirable for the point of care devices (POC) $)^{29,30}$.

\section{Sensing in the Presence of Target and Noise Molecules}

A clinical analyte solution contains both target as well as noise molecules which can react simultaneously with the receptors. For instance, roughly $99 \%, 97 \%, 87 \%$ and $20 \%$ biomarkers for ovary, breast, prostate and lung cancer respectively are estimated to be proteins, many of which interfere via cross-reactions during target detection ${ }^{31,32}$. For example, CA-125 is a well-known cancer biomarker which belongs to the family of Carcinoembryonic antigen (CEA), a set of highly related glycoproteins which often give false positives due to non-specific binding from noise molecules present in similar order of concentration $^{33-35}$. The reaction kinetics for simultaneous target and noise reaction where, $\mathrm{b}$ is the analyte-receptor complex concentration, $b_{m}$ is the maximum number of receptor sites is described as:

$$
\frac{\mathrm{db}_{1}(\mathrm{t})}{\mathrm{dt}}=\mathrm{k}_{\mathrm{on} 1} \mathrm{C}_{\mathrm{o} 1}\left(\mathrm{~b}_{\mathrm{m}}-\mathrm{b}_{1}(\mathrm{t})-\mathrm{b}_{2}(\mathrm{t})\right)-\mathrm{k}_{\mathrm{off} 1} \mathrm{~b}_{1}(\mathrm{t})
$$




$$
\begin{gathered}
\left.\frac{\mathrm{db}_{2}(\mathrm{t})}{\mathrm{dt}}=\mathrm{k}_{\mathrm{on} 2} \mathrm{C}_{\mathrm{o} 2}\left(\mathrm{~b}_{\mathrm{m}}-\mathrm{b}_{2}(\mathrm{t})-\mathrm{b}_{1}(\mathrm{t})\right)\right)-\mathrm{k}_{\mathrm{off}} \mathrm{b}_{2} \\
\frac{\mathrm{b}_{1 \mathrm{eq}}}{\mathrm{b}_{\mathrm{m}}}=\frac{\mathrm{C}_{\mathrm{o} 1} / \mathrm{K}_{\mathrm{d} 1}}{1+\mathrm{C}_{\mathrm{o} 1} / \mathrm{K}_{\mathrm{d} 1}+\mathrm{C}_{\mathrm{o} 2} / \mathrm{K}_{\mathrm{d} 2}} ; \frac{\mathrm{b}_{2 \mathrm{eq}}}{\mathrm{b}_{\mathrm{m}}}=\frac{\mathrm{C}_{\mathrm{o} 2} / \mathrm{K}_{\mathrm{d} 2}}{1+\mathrm{C}_{\mathrm{o} 1} / \mathrm{K}_{\mathrm{d} 1}+\mathrm{C}_{\mathrm{o} 2} / \mathrm{K}_{\mathrm{d} 2}}
\end{gathered}
$$

The reaction of target $\left(b_{1}\right)$ and noise $\left(b_{2}\right)$ molecules with the receptor sites progresses as per Eq. 9, Eq. 10, where, the respective equilibrium concentration is given by Eq. 11. The analytical expression of equilibrium time for a two-component reaction consisting of target and noise molecule is overly complicated to guide any further. Therefore, the binding kinetics over sensor surface in the presence of noise molecules is simulated to gain further insight.

We have studied the target-receptor binding kinetics in the presence of noise molecules by varying forward and backward reaction rate (Fig. 4). The forward reaction rate and concentration of both target and noise molecules is fixed $\mathrm{K}_{\mathrm{on}}=10^{5} \mathrm{M}^{-1} \mathrm{~s}^{-1}, \mathrm{C}_{\mathrm{o}}=100 \mathrm{nM}$ where, backward reaction rate of noise molecule is varied $\mathrm{K}_{\mathrm{off}}=10^{-1}-10^{-3} \mathrm{~s}^{-1}$. The concentration of target molecules (smooth curves) clearly diverges from the noise molecules (broken curves) as shown in Fig. 4(a) resulting in a clear delineation of target-receptor and noise-receptor binding kinetics. Interestingly, binding kinetics of target and noise molecules merge on further decrease in the backward reaction rate of target $\left(\mathrm{K}_{\mathrm{off}}=10^{-6} \mathrm{~s}^{-1}\right)$ and noise $\left(\mathrm{K}_{\mathrm{off}}=10^{-5} \mathrm{~s}^{-1}\right)$ molecules (Fig. 4(b)) which implies target biomarker molecules can't be specifically detected in the presence of noise molecules.

The reaction kinetics in the presence of target and noise molecules proceed according to Eq. 9 and Eq. 10, where the ratio of bound target and noise molecules is given as $\frac{\mathrm{b}_{1 \mathrm{eq}}}{\mathrm{b}_{2 \mathrm{eq}}}=\frac{\mathrm{C}_{\mathrm{o} 1} / \mathrm{K}_{\mathrm{d} 1}}{\mathrm{C}_{\mathrm{o} 2} / \mathrm{K}_{\mathrm{d} 2}}$ (Eq. 11). At equilibrium bound target molecules $\left(\mathrm{b}_{1 \mathrm{eq}}\right)$ will be always larger than bound noise molecules $\left(b_{2 \mathrm{eq}}\right)$ since $\mathrm{K}_{\mathrm{d} 1}<\mathrm{K}_{\mathrm{d} 2}$. However, the time required for the reactions to achieve equilibrium can be much higher in the case of lower backward reaction rate (Fig. 4(b)) which isn't desirable for a POC device. Further, the target and noise binding kinetics interfere with each other only if the bound target and noise molecules become comparable to surface sites i.e. $b_{m} \approx b_{1}(t)$ or $b_{2}(t)$ as inferred from Eq. 9 and Eq. 10. Hence, the initial phase of target and noise binding kinetics progresses as if there is no other molecule is present. As the $\mathrm{D}_{\mathrm{a}} \approx 0.05 \ll 1$ for the target molecule $\left(\mathrm{K}_{\mathrm{on}}=10^{5} \mathrm{M}^{-1} \mathrm{~s}^{-1}\right)$, the typical time up to which the reactions proceed independently is given by Eq. 7 i.e. $\tau_{\text {eq }}=\left(\mathrm{K}_{\text {off }}+\right.$ $\left.\mathrm{K}_{\mathrm{on}} \mathrm{C}_{\mathrm{o}}\right)^{-1}$. Since $\mathrm{K}_{\mathrm{on}} \mathrm{C}_{\mathrm{o}} \gg \mathrm{K}_{\mathrm{off}}$ for all values of target and noise molecules, we can see that the initial binding kinetics of target and noise molecules merge in Fig. 4(a) and Fig. 4(b) as 
$\mathrm{K}_{\mathrm{on}}$ is fixed and $\tau_{\mathrm{eq}}=\left(\mathrm{K}_{\mathrm{on}} \mathrm{C}_{\mathrm{o}}\right)^{-1}$. Later on, as the time progresses the reaction tilts toward target-receptor complex which is limited by the unbinding rate of noise molecules $\left(1 / \mathrm{K}_{\mathrm{off}}\right)$. The unbinding time-scale of noise molecules with $\mathrm{K}_{\mathrm{off}}=10^{-4}, 10^{-5} \mathrm{~s}^{-1}$ is $10^{4}, 10^{5} \mathrm{sec}$ respectively making it impossible to specifically detect the target molecule within a reasonable time of $1000 \mathrm{sec}$.
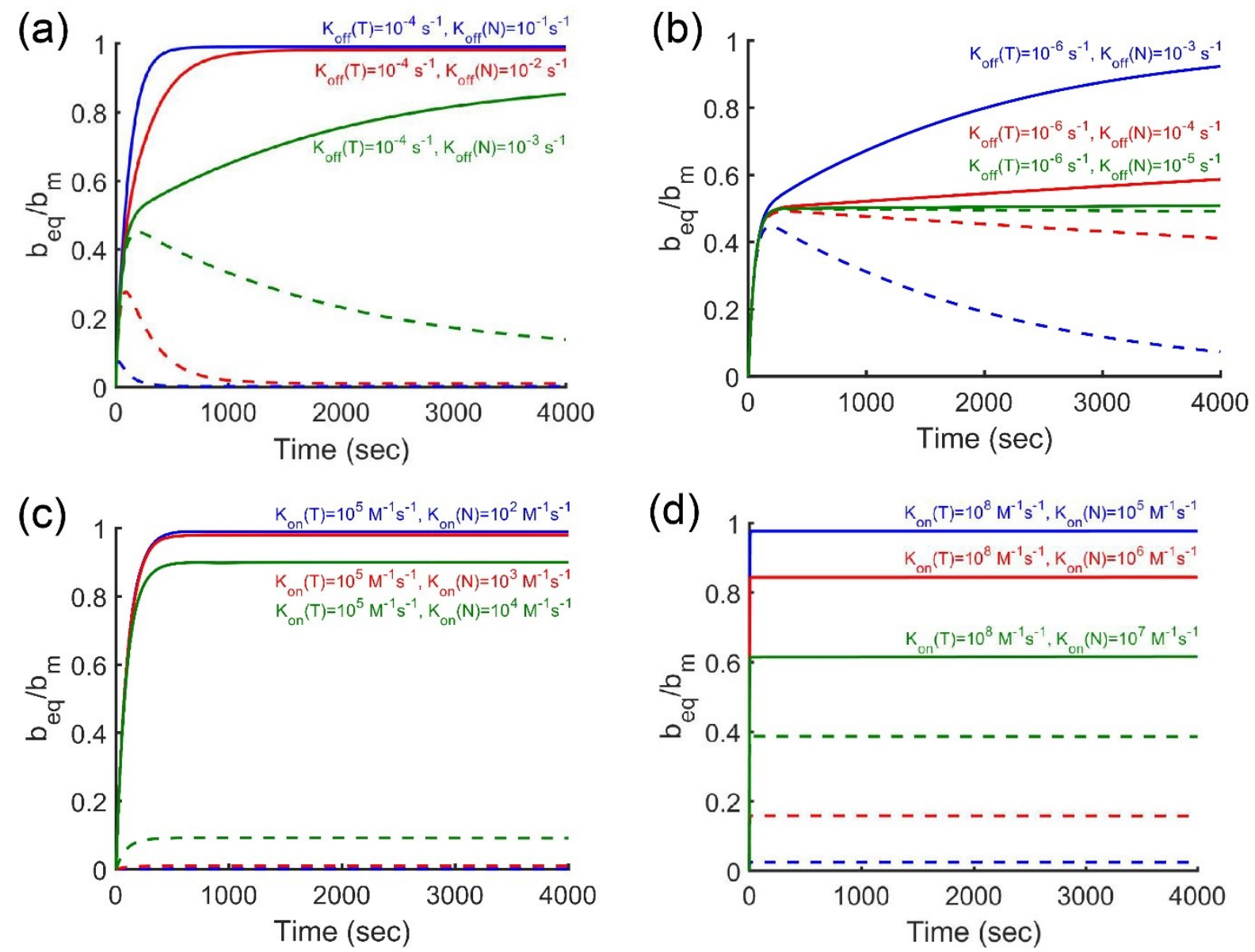

FIG. 4. The target (smooth curves) and noise-receptor (broken curves) binding kinetics, where, concentration of both target and noise molecule is $100 \mathrm{nM}$. Reaction parameters: (a) Target molecule - $\mathrm{K}_{\mathrm{on}}=10^{5} \mathrm{M}^{-1} \mathrm{~s}^{-1}, \mathrm{~K}_{\mathrm{off}}=10^{-4} \mathrm{~s}^{-1}$; Noise molecule - $\mathrm{K}_{\mathrm{on}}=10^{5} \mathrm{M}^{-1} \mathrm{~s}^{-1}, \mathrm{~K}_{\text {off }}$ (varied $)=10^{-1}$ $10^{-3} \mathrm{~s}^{-1}$. (b) Target molecule - $\mathrm{K}_{\mathrm{on}}=10^{5} \mathrm{M}^{-1} \mathrm{~s}^{-1}, \mathrm{~K}_{\mathrm{off}}=10^{-6} \mathrm{~s}^{-1}$; Noise molecule - $\mathrm{K}_{\mathrm{on}}=$ $10^{5} \mathrm{M}^{-1} \mathrm{~s}^{-1}, \mathrm{~K}_{\text {off }}$ (varied) $=10^{-3}-10^{-5} \mathrm{~s}^{-1}$. (c) Target molecule $-\mathrm{K}_{\mathrm{on}}=10^{5} \mathrm{M}^{-1} \mathrm{~s}^{-1}, \mathrm{~K}_{\text {off }}=10^{-4} \mathrm{~s}^{-1}$; Noise molecule - $\mathrm{K}_{\mathrm{on}}$ (varied $)=10^{2}-10^{4} \mathrm{M}^{-1} \mathrm{~s}^{-1}, \mathrm{~K}_{\mathrm{off}}=10^{-4} \mathrm{~s}^{-1}$. (d) Target molecule $-\mathrm{K}_{\mathrm{on}}=$ $10^{8} \mathrm{M}^{-1} \mathrm{~s}^{-1}, \mathrm{~K}_{\text {off }}=10^{-6} \mathrm{~s}^{-1}$; Noise molecule $-\mathrm{K}_{\text {on }}$ (varied $)=10^{5}-10^{7} \mathrm{M}^{-1} \mathrm{~s}^{-1}, \mathrm{~K}_{\text {off }}=10^{-6} \mathrm{~s}^{-1}$.

Similarly, we probe the interference of noise molecule of various forward reaction rate $\left(\mathrm{K}_{\mathrm{on}}=10^{2}-10^{4} \mathrm{M}^{-1} \mathrm{~s}^{-1}\right)$ at a fixed backward reaction rate $\left(\mathrm{K}_{\mathrm{off}}=10^{-4} \mathrm{~s}^{-1}\right)$ of target $\left(\mathrm{K}_{\mathrm{on}}=10^{5} \mathrm{M}^{-1} \mathrm{~s}^{-1}\right)$ and noise molecules as shown in Fig. 4(c). Again, the initial target and noise binding kinetics will progress independently with forward reaction time scale of $\tau_{\mathrm{eq}}=$ $\left(\mathrm{K}_{\mathrm{on}} \mathrm{C}_{\mathrm{o}}\right)^{-1}$. Accordingly, we can see in Fig. 4(c), the concentration profile for different $\mathrm{K}_{\mathrm{on}}$ is well separated. For even higher forward reaction rates of target $\mathrm{K}_{\mathrm{on}}=10^{8} \mathrm{M}^{-1} \mathrm{~s}^{-1}$ and 
noise molecules $\mathrm{K}_{\mathrm{on}}=10^{6}, 10^{7}, 10^{8} \mathrm{M}^{-1} \mathrm{~s}^{-1}$ at a fixed $\mathrm{K}_{\mathrm{off}}=10^{-6} \mathrm{~s}^{-1}$, the system transitions into the transport limited regime i.e. $\mathrm{D}_{\mathrm{a}} \gg 1$. Accordingly, the equilibrium time is given by Eq. 8 and the dependency on higher values of $\mathrm{K}_{\mathrm{on}}$ progressively decreases as shown in Fig. 4(d). Afterwards, no change in the concentration of target and noise-receptor binding kinetics is observed since, the unbinding time-scale $\left(1 / \mathrm{K}_{\text {off }}\right)$ of noise molecules is of the order of $10^{6} \mathrm{sec}$.

The reaction parameters $\mathrm{K}_{\mathrm{on}}>10^{4} \mathrm{M}^{-1} \mathrm{~s}^{-1}$ and $\mathrm{K}_{\mathrm{off}}<10^{-4} \mathrm{~s}^{-1}$ exhibiting high interference comprises over $60 \%$ and $20 \%$ of the reported protein-ligand binding affinities respectively $^{32,36}$. Further, several biomolecules are structurally similar and differ only with regards to their active sites. As a result, the forward reaction rates $\left(\mathrm{K}_{\mathrm{on}}\right)$ is similar for both noise and target biomolecule resulting in binding kinetics to be dependent solely on the backward reaction rate $\left(\mathrm{K}_{\mathrm{off}}\right)$. For instance, CA2 (Carbonic Anhydrase II) is a biomarker for gastrointestinal tumor that is present along with other noise molecules i.e. CA7, CA9, CA12 $2^{37-39}$. The forward reaction rate with respect to the ligand, 4-[(Pyrimidin-2Ylsulfanyl)acetyl] benzenesulfonamide, in all cases is $\approx 10^{6} \mathrm{M}^{-1} \mathrm{~s}^{-1}$, accordingly, the specificity of CA2 detection relies only on the relative concentration and backward reaction rates $^{31}$.

\section{Identifying Appropriate Biomarker for a Microfluidic POC Device}

The prominent biomarkers of various diseases are generally proteins that are present in either equal or lower concentrations as compared to the other similar and highly related proteins which make their specific detection a difficult task. The ratio of the equilibrium concentration of target and noise receptor complex as explained previously is $b_{1 \mathrm{eq}} / \mathrm{b}_{2 \mathrm{eq}}=$ $\mathrm{C}_{\mathrm{o} 1} \mathrm{~K}_{\mathrm{d} 2} / \mathrm{C}_{\mathrm{o} 2} \mathrm{~K}_{\mathrm{d} 1}$, therefore, a target biomarker can be reliably detected either if they are more in numbers $\left(\mathrm{C}_{\mathrm{o} 1} \gg \mathrm{C}_{\mathrm{o} 2}\right)$ or have a stronger binding kinetics $\left(\mathrm{K}_{\mathrm{d} 1} \ll \mathrm{K}_{\mathrm{d} 2}\right)$ as compared to the noise molecules. The common POC biosensors for diabetes or pregnancy related test relies on the spikes in biomarker concentration. For instance, the level of pregnancy biomarker 'human chorionic gonadotropin' (hCG) jumps 10000 folds from 5 mIU/mL to 50000 mIU/ $\mathrm{mL}$ within six weeks of pregnancy ${ }^{40}$. In contrast, the concentration of cancer biomarkers in the early stage of disease is very low $(\sim \mathrm{pM})$ and is in the similar concentration range as that of other similar biomolecules ${ }^{2,41}$. The presence of target molecules in low concentration sets stringent conditions on specific detection. In such scenario it is important to identify the 
reaction parameters where, specific detection is fundamentally limited by reaction kinetics up to a reasonable time-scale e $^{42,43}$.

We have previously shown that the initial phase of target and noise receptor binding kinetics progress independently and with time the equilibrium shifts in the favour of stronger reaction (target-receptor complex) regulated by the unbinding time scale $\left(1 / \mathrm{K}_{\mathrm{off}}\right)$ of noise molecules. Therefore, a reasonable prediction can be made by utilizing our understanding of individual target and noise-receptor binding kinetics. The equilibrium concentration and time (Log-Log plot) calculated at various $K_{o n}$ and $K_{o f f}$ and analyte concentrations of $p M, n M, \mu M$ is shown in Fig. 5. The circled portion in the Fig. 5(a), Fig. 5(c) and Fig. 5(e) indicates the reaction regime, $\mathrm{K}_{\mathrm{on} 1,2} \mathrm{C}_{\mathrm{o} 1,2} \gg \mathrm{K}_{\mathrm{off} 1,2}$ (Eq. 4 ), which satisfies the condition of $\mathrm{b}_{1 \mathrm{eq}}, \mathrm{b}_{2 \mathrm{eq}} \approx \mathrm{b}_{\mathrm{m}}$ and is not conducive for a specific detection. The circled area representing the reaction regime is prone to interference and progressively increases as the analyte concentration increases from pM, nM to $\mu \mathrm{M}$ as shown in Fig. 5(a), Fig. 5(c) and Fig. 5(e) respectively.

(a)

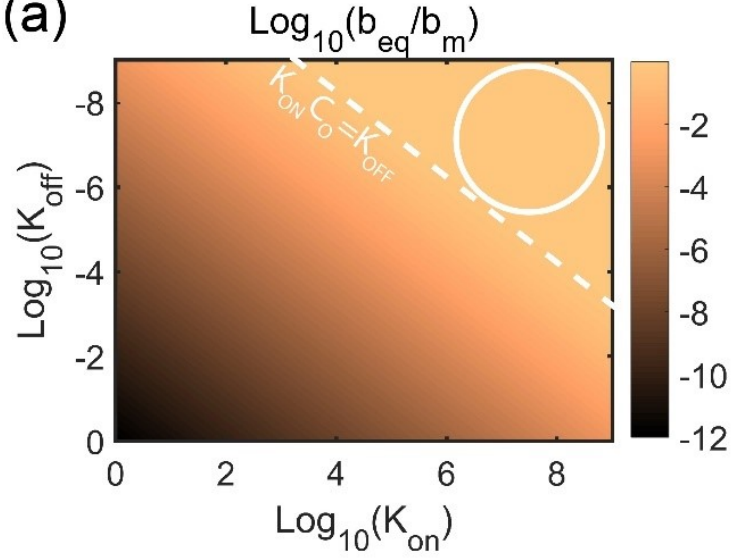

(c)

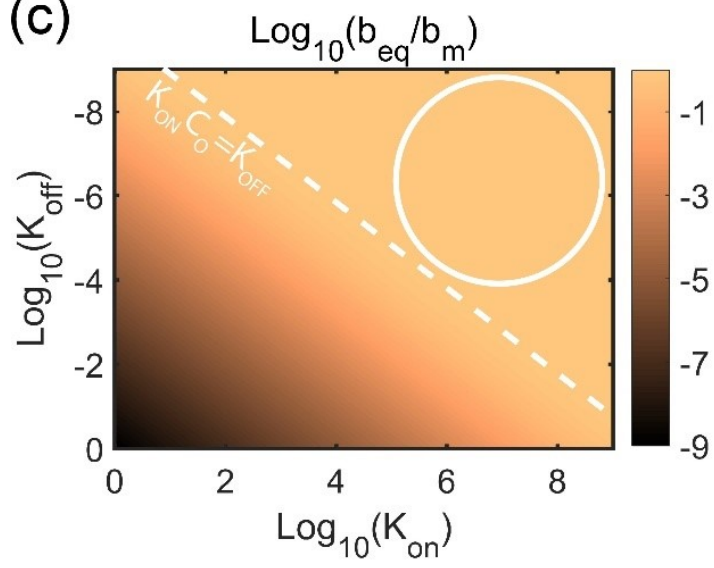

(b)
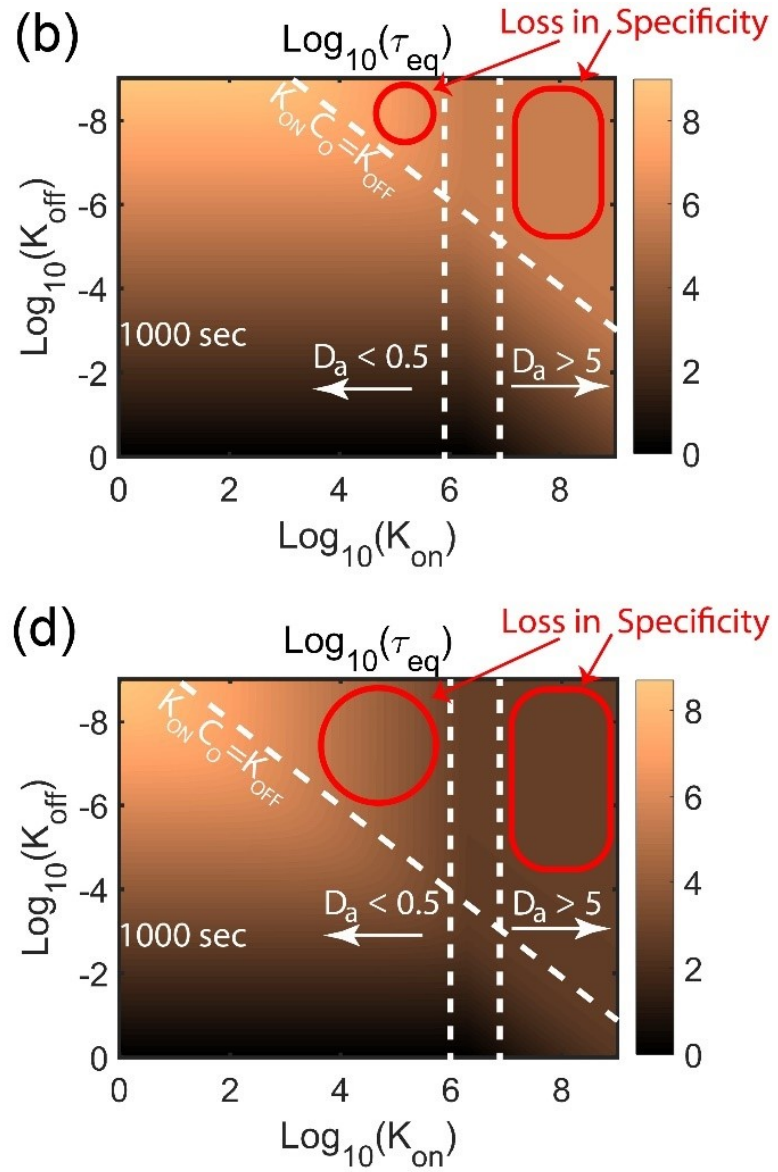

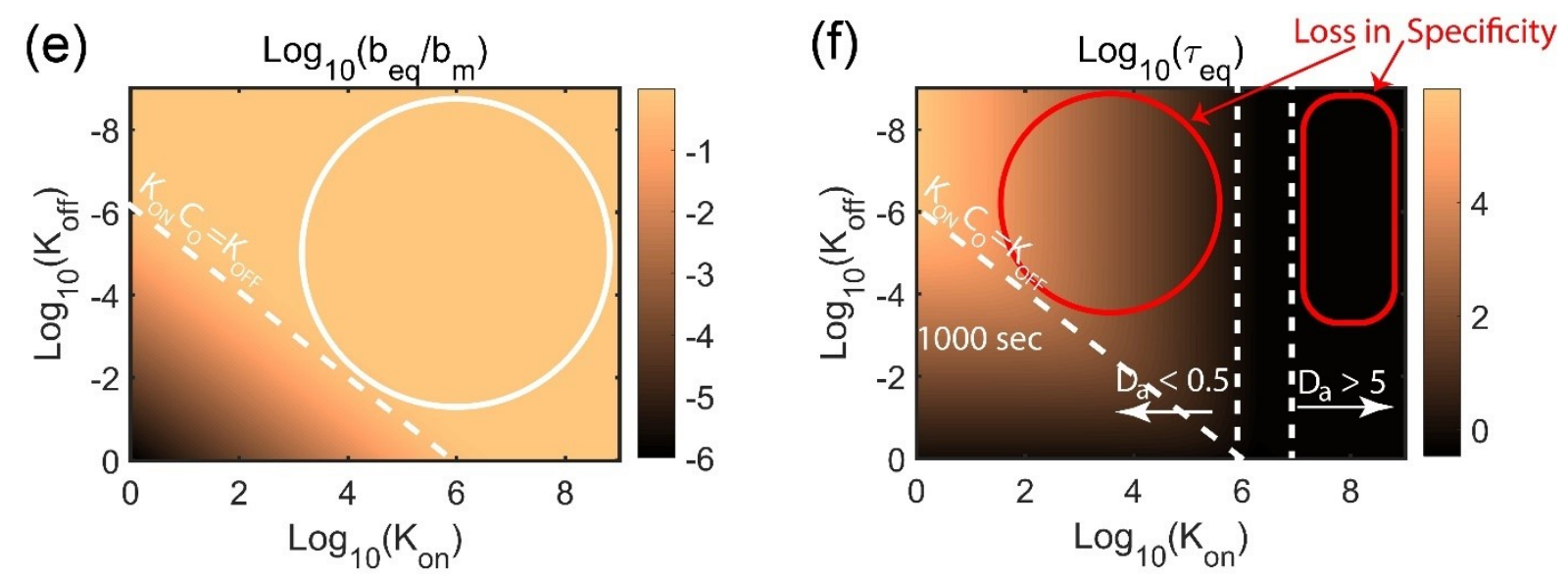

FIG. 5. Log plot of equilibrium concentration $(\mathrm{a}, \mathrm{c}, \mathrm{e})$ having corresponding analyte concentration $1 \mathrm{pM}, 1 \mathrm{nM}, 1 \mu \mathrm{M}$ - white encircled portion indicates that the sensor saturates if $\mathrm{K}_{\mathrm{on}} \mathrm{C}_{\mathrm{o}} \gg \mathrm{K}_{\text {off }}$ and is prone to interference. Log plot of equilibrium time $(b, d, f)$ having corresponding analyte concentration $1 \mathrm{pM}, 1 \mathrm{nM}, 1 \mu \mathrm{M}$ - red encircled portion indicates the reaction parameter regime where target and noise-receptor binding kinetics merge, if $\mathrm{K}_{\mathrm{on}} \mathrm{C}_{\mathrm{o}} \gg \mathrm{K}_{\text {off }}$ and $\mathrm{D}_{\mathrm{a}} \gg 1$. The reaction parameters encircled in red exhibits loss in specificity which covers increasingly large portion of phase space as the concentration is increased in figure (b), (d), (f) respectively.

The equilibrium time is displayed in Fig. 5(b), Fig. 5(d) and Fig. 5(f), where, high interference regime $\left(\mathrm{K}_{\mathrm{on} 1,2} \mathrm{C}_{\mathrm{o} 1,2} \gg \mathrm{K}_{\mathrm{off} 1,2}\right)$ is appropriately marked. The reaction parameter phase space exhibiting loss in specificity of target biomarker molecule detection is explained as follows:

a) Reaction limited condition $\left(D_{a} \ll 1\right)$ :

The equilibrium time for analyte molecules over the sensor surface (Log-Log plot) at various $\mathrm{K}_{\mathrm{on}}$ and $\mathrm{K}_{\mathrm{off}}$ and analyte concentrations (pM, nM, $\left.\mu \mathrm{M}\right)$ are shown in Fig. 5(b), Fig. 5(d) and Fig. 5(f) respectively. The dependency of equilibrium time $\left(\tau_{\text {eq } 1,2} \approx\left(\mathrm{K}_{\mathrm{on} 1,2} \mathrm{C}_{\mathrm{o} 1,2}\right)^{-1}\right)$ on backward reaction rate $\left(\mathrm{K}_{\mathrm{off}}\right)$ vanishes under high interference $\left(\mathrm{K}_{\mathrm{on} 1,2} \mathrm{C}_{\mathrm{o1,2}} \gg \mathrm{K}_{\mathrm{off1}, 2}\right)$ and reaction limited condition $\left(D_{a} \ll 1\right)$. Hence, if the concentration of target and the noise molecules are similar $\left(\mathrm{C}_{\mathrm{O} 1} \approx \mathrm{C}_{\mathrm{O} 2}\right)$, then the target and noise-receptor binding kinetics would merge for similar forward reaction rate $\left(\mathrm{K}_{\mathrm{on} 1,2}\right)$. The encircled circular region in red between the line marked by $\mathrm{K}_{\mathrm{on}} \mathrm{C}_{\mathrm{o}}=\mathrm{K}_{\mathrm{off}}$ and $\mathrm{D}_{\mathrm{a}}<0.5$ in Fig. 5(b), Fig. 5(d) and Fig. 5(f) satisfies above condition and hence, the target and noise receptor binding kinetics can't be differentiated based on backward reaction rate $\left(K_{o f f 1,2}\right)$ within $1000 \mathrm{sec}$.

b) Transport limited condition $\left(D_{a} \gg 1\right)$ : 
The dependency of equilibrium time $\left(\tau_{\text {eq1,2 }} \approx \frac{\mathrm{b}_{\mathrm{m}} \mathrm{l}_{\mathrm{s}}}{\mathrm{DF \mathcal {F }} \mathrm{C}_{\mathrm{o}}}\right)$ on reaction rates $\mathrm{K}_{\mathrm{on}}$ and $\mathrm{K}_{\mathrm{off}}$ vanishes under high interference $\left(\mathrm{K}_{\mathrm{on} 1,2} \mathrm{C}_{\mathrm{o} 1,2} \gg \mathrm{K}_{\mathrm{off} 1,2}\right)$ and transport limited condition $\left(\mathrm{D}_{\mathrm{a}} \gg 1\right)$. Accordingly, if the concentration of target and receptor molecules are similar $\left(\mathrm{C}_{01} \approx \mathrm{C}_{\mathrm{o} 2}\right)$ then target and noise-receptor binding kinetics merge upto equilibrium time regardless of the reaction rate constants $\left(\mathrm{K}_{\mathrm{on} 1,2}, \mathrm{~K}_{\mathrm{off} 1,2}\right)$. The region beyond the line marked by $\mathrm{K}_{\mathrm{on}} \mathrm{C}_{\mathrm{o}} \gg \mathrm{K}_{\mathrm{off}}$ and $\mathrm{D}_{\mathrm{a}}>5$ in Fig. 5(b), Fig. 5(d) and Fig. 5(f) satisfies this condition and thus the target and noise-receptor binding kinetics can't be differentiated up to equilibrium time. The reaction regime encircled in red beyond $\mathrm{D}_{\mathrm{a}}>5$ as shown in Fig. 5(b), Fig. 5(d) and Fig. 5(f) has unbinding time-scale larger than $1000 \mathrm{sec}$ and is not suitable for target detection with respect to the reaction rates $\mathrm{K}_{\mathrm{on} 1,2}$ and $\mathrm{K}_{\mathrm{off} 1,2}$.

To summarize, we have first established $\mathrm{K}_{\mathrm{on} 1,2} \mathrm{C}_{01,2} \gg \mathrm{K}_{\mathrm{off} 1,2}$ as the reaction regime having high noise interference. In this condition if the target and noise molecules are present in similar concentrations $\left(\mathrm{C}_{\mathrm{O} 1} \approx \mathrm{C}_{\mathrm{O} 2}\right)$ then the target specificity with respect to the backward reaction rate $\left(\mathrm{K}_{\mathrm{off}}\right)$ is lost in reaction limited regime $\left(\mathrm{D}_{\mathrm{a}}<0.5\right)$. Further, the specificity is lost both with respect to $K_{o n}$ and $K_{o f f}$ in transport limited regime $\left(D_{a}>5\right)$. The loss of specificity in both the reaction and transport limited regime is up to equilibrium time-scale and can persist further for larger unbinding time scale of noise molecule $\left(1 / \mathrm{K}_{\mathrm{off}}\right)$. Perhaps the most remarkable finding from this exercise is the region signifying complete loss in specificity (marked region in red beyond $\mathrm{D}_{\mathrm{a}}>5$ in Fig. 5(b), Fig. 5(d) and Fig. 5(f) increases with increase in concentration and lies towards the stronger reaction i.e. high $\mathrm{K}_{\mathrm{on}}$ and low $\mathrm{K}_{\mathrm{off}}$ implying low concentrations and weak reactions are more suited for specific detection.

\section{CONCLUSION}

Medical diagnostics relies on the efficient detection of target analytes by the biosensors and bioanalytical devices. In this study, we establish the reaction regimes, where, the detection of target biomarker in the presence of noise molecules is not possible within $1000 \mathrm{sec}$. We pedagogically developed the understanding of binding kinetics for multiple analyte molecules and established that the conventional wisdom of high analyte (target, noise) concentration and stronger reaction (high $\mathrm{K}_{\mathrm{on}}$, low $\mathrm{K}_{\mathrm{off}}$ ) are not suited for specific detection. The presented semi-analytical approach towards the understanding of binding kinetics in the presence of multiple analyte molecules will help in narrowing down the choice of biomarkers for the POC devices. 


\section{REFERENCES}

${ }^{1}$ H. Nishiura, Emerg. Themes Epidemiol 4, 2, (2007).

${ }^{2}$ K.L. Terry, H. Schock, R.T. Fortner, A. Hu sing, R.N. Fichorova, H.S. Yamamoto, A.F. Vitonis, T. Johnson, K. Overvad, A. Tjonneland, M.-C. Boutron-Ruault, S. Mesrine, G. Severi, L. Dossus, S. Rinaldi, H. Boeing, V. Benetou, P. Lagiou, A. Trichopoulou, V. Krogh, E. Kuhn, S. Panico, H.B. Bueno-de-Mesquita, N.C. Onland-Moret, P.H. Peeters, I.T. Gram, E. Weiderpass, E.J. Duell, M.-J. Sanchez, E. Ardanaz, N. Etxezarreta, C. Navarro, A. Idahl, E. Lundin, K. Jirstro m, J. Manjer, N.J. Wareham, K.-T. Khaw, K.S. Byrne, R.C. Travis, M.J. Gunter, M.A. Merritt, E. Riboli, D.W. Cramer, and R. Kaaks, Clin. Cancer Res. 22, 4664 (2016).

${ }^{3}$ A.K. Wanekaya, W. Chen, N.V. Myung, and A. Mulchandani, Electroanalysis 18, 533 (2006).

${ }^{4}$ D.J. Bornhop, J.C. Latham, A. Kussrow, D.A. Markov, R.D. Jones, and H.S. Sørensen, Science 317, 1732 (2007).

${ }^{5}$ R. Raiteri, M. Grattarola, H.-J. Butt, and P. Skládal, Sensors Actuators B Chem. 79, 115 (2001).

${ }^{6}$ T. Lee, Lee, and T. Ming-Hung, Sensors 8, 5535 (2008).

${ }^{7}$ P.Y. Lee, J. Costumbrado, C.-Y. Hsu, and Y.H. Kim, J. Vis. Exp 62, (2012).

${ }^{8}$ M. Bantscheff, M. Schirle, G. Sweetman, J. Rick, and B. Kuster, Anal. Bioanal. Chem. 389, 1017 (2007).

${ }^{9}$ K.N. Han, C.A. Li, and G.H. Seong, Annu. Rev. Anal. Chem. 6, 119 (2013).

${ }^{10}$ P.J. Tighe, R.R. Ryder, I. Todd, and L.C. Fairclough, PROTEOMICS - Clin. Appl. 9, 406 (2015).

${ }^{11}$ J. Shan, J. Li, X. Chu, M. Xu, F. Jin, X. Wang, L. Ma, X. Fang, Z. Wei, and X. Wang, RSC Adv. 8, 7942 (2018).

${ }^{12}$ K. Louchis and S. O’Driscoll, Annu. Int. Conf. IEEE Eng. Med. Biol. Soc., 7670 (2011).

${ }^{13}$ T. Chard, Hum. Reprod. 7, 701 (1992).

${ }^{14}$ R. Wilson, Expert Rev. Proteomics 10, 135 (2013). 
${ }^{15}$ M.M. Varma, arxiv, (2015).

${ }^{16}$ T.M. Squires, R.J. Messinger, and S.R. Manalis, Nat. Biotechnol. 26, 417 (2008).

${ }^{17}$ A.I. Barbosa and N.M. Reis, Analyst 142, 858 (2017).

${ }^{18}$ N.K. Rajan, S. Rajauria, T. Ray, S. Pennathur, and A.N. Cleland, Biosens. Bioelectron. 77, 1062 (2016).

${ }^{19}$ S.P. Mulvaney, C.L. Cole, M.D. Kniller, M. Malito, C.R. Tamanaha, J.C. Rife, M.W. Stanton, and L.J. Whitman, Biosens. Bioelectron. 23, 191 (2007).

${ }^{20}$ H.C. Tekin, M. Cornaglia, and M. a M. Gijs, Lab Chip 13, 1053 (2013).

${ }^{21}$ P. Prakash, S. Pahal, and M. Varma, Macromol. Chem. Phys. 219, 1700543 (2018).

${ }^{22}$ Robert B. Bird, W.E. Stewart, and E.N. Lightfoot, Transport Phenomena, Wiley (2007).

${ }^{23}$ B. Kirby, Micro- and Nanoscale Fluid Mechanics, Cambridge University Press (2010).

${ }^{24}$ P. Prakash and M. Varma, Sci. Rep. 7, 15754 (2017).

${ }^{25}$ L.G. Leal, Advanced Transport Phenomena, Cambridge University Press, (2007).

${ }^{26}$ J. Newman, The Fundamental Principles of Current Distribution and Mass Transport in Electrochemical Cells, Marcel Dekker (1973).

${ }^{27}$ R. Hansen, H. Bruus, T.H. Callisen, and O. Hassager, Langmuir 28, 7557 (2012).

${ }^{28}$ M. Arrio-Dupont, S. Cribier, G. Foucault, P.F. Devaux, and A. D 'albis, Biophys. J. 70, 2327 (1996).

${ }^{29}$ B. Esteban Fernández de Ávila, H.M. Watkins, J.M. Pingarrón, K.W. Plaxco, G. Palleschi, and F. Ricci, Anal. Chem. 85, 6593 (2013).

${ }^{30}$ I. Álvarez-Martos and E.E. Ferapontova, Anal. Chem. 88, 3608 (2016).

${ }^{31}$ Biomarkers — EDRN Public Portal https://edrn.nci.nih.gov/biomarkers.

${ }^{32}$ M. Polanski and N.L. Anderson, Biomark. Insights 1, 1 (2007).

${ }^{33}$ C.M. Coticchia, J. Yang, and M.A. Moses, J. Natl. Compr. Canc. Netw. 6, 795 (2008).

${ }^{34}$ E.L. Moss, J. Hollingworth, and T.M. Reynolds, J. Clin. Pathol. 58, 308 (2005).

${ }^{35}$ G. Sölétormos, M.J. Duffy, S. Othman Abu Hassan, R.H.M. Verheijen, B. Tholander, R.C. 
Bast, K.N. Gaarenstroom, C.M. Sturgeon, J.M. Bonfrer, P.H. Petersen, H. Troonen, G. CarloTorre, J. Kanty Kulpa, M.K. Tuxen, R. Molina, and R. Molina, Int. J. Gynecol. Cancer 26, 43 (2016).

${ }^{36}$ T. Liu, Y. Lin, X. Wen, R.N. Jorissen, and M.K. Gilson, Nucleic Acids Res. 35, D198 (2007).

${ }^{37}$ S. Parkkila, J. Lasota, J.A. Fletcher, W. Ou, A.J. Kivelä, K. Nuorva, A.-K. Parkkila, J. Ollikainen, W.S. Sly, A. Waheed, S. Pastorekova, J. Pastorek, J. Isola, and M. Miettinen, Mod. Pathol. 23, 743 (2010).

${ }^{38}$ M. Leppilampi, J. Saarnio, T.J. Karttunen, J. Kivelä, S. Pastoreková, J. Pastorek, A. Waheed, W.S. Sly, and S. Parkkila, World J. Gastroenterol. 9, 1398 (2003).

${ }^{39}$ D. Dovile, L. Rita, Z. Milda, J. Vaida, M. Vilma, P. Seppo, M. Daumantas, and Z. Aurelija, Front. Immunol. 4, (2013).

${ }^{40}$ T.I.M. Korevaar, E.A.P. Steegers, Y.B. de Rijke, S. Schalekamp-Timmermans, W.E. Visser, A. Hofman, V.W. V. Jaddoe, H. Tiemeier, T.J. Visser, M. Medici, and R.P. Peeters, Eur. J. Epidemiol. 30, 1057 (2015).

${ }^{41}$ J.F. Rusling, C. V Kumar, J.S. Gutkind, and V. Patel, Analyst 135, 2496 (2010).

${ }^{42}$ J.L.V. Shaw, Pract. Lab. Med. 4, 22 (2016).

${ }^{43}$ A. St John and C.P. Price, Clin. Biochem. Rev. 35, 155 (2014). 